\title{
DEVELOPMENT OF COMMUNICATIONAL SKILLS (READING, WRITING, SPEAKING) IN ESP CLASSES AT ANDIJAN STATE MEDICAL INSTITUTE
}

${ }^{\mathbf{1}}$ Gulbahor Oybek kizi Yahshiboyeva, ${ }^{2}$ Jamila Sharipovna Djumabayeva

${ }^{1}$ Lecturer, Department of Foreign Languages, Andijan State Medical Institute, Andijan, Uzbekistan.

E-mail: daminovamubina@inbox.ru

${ }^{2}$ Associate Professor, National University of Uzbekistan named after Mirzo Ulugbek, Tashkent, Uzbekistan.

\section{ABSTRACT}

There is a rapid and intensive development of medical science. In accordance with this, new goals and objectives are being put forward in the training of medical specialists, which are reflected in Uzbek standards of higher professional medical education (ASMI). These goals and objectives concern not only specialized medical disciplines, but also disciplines of the basic general education cycle. The article discusses the concept of listening; the relationship with other types of speech activity, the types and stages of listening, and also provides example exercises for the development and improvement of this skill in Andijan state medical institute (ASMI) among pharmacy students.

In the past few years, teaching communication at the ASMI in English has been a primary task for institute students. In the medical world, English is considered not just a foreign language, but an international language, knowledge of which is necessary to obtain a decent education, a well-paid profession and communication at the international level.

Keywords:

self-improvement, radio broadcast, lexico-syntactic and grammatical features, reading-emphasizes, ASMI, Writing Across the Curriculum

Article Received: 18 October 2020, Revised: 3 November 2020, Accepted: 24 December 2020

\section{Introduction}

Currently, in the period of globalization and the formation of a single information space, knowledge of a foreign language, and first of all English, is becoming an integral part of the characteristics of a highly qualified specialist. Almost all scientific discoveries made in the world are subsequently described in English. Therefore, no one doubts that knowledge of the English language in the modern world is the path to self-improvement, professional growth and international activity. Any person engaged in scientific activity should be at the center of all the latest achievements in their field. This primarily applies to medical professionals.

Recently, most attention has been paid to teaching auditorium skills, since fluency in a language also presupposes a fluent understanding of English by different sense organs, mostly listening. Possession of this type of speech activity helps a person to hear and understand the speaker, to extract the necessary information for himself, to respond to the speech of the interlocutor, and also to pronounce the necessary information, which in turn is speaking.

Materials and Methods

Learning any language (non-native), primarily native, begins with listening, we hear sounds, words, perceive any flow of information by ear, only then we learn to reproduce speech (speaking), later we learn reading and writing skills. Thus, listening is an important and first link in the language during the learning process. Listening is present in every lesson in our medical institute - this is the teacher's speech, the students' answers, sometimes lecturers' audio records.

Listening to audio recordings is in the future a main basic part for the development of speaking skills, writing skills and even in reading skills. During our lessons we also use presentation and in this case, listening plays a secondary role. The main factor in listening teaching is motivation. The listener must have a need for listening comprehension. It is important to choose 
suitable audio text that will be interesting and informative for students (for example, a text of a medical purpose), will correspond to their age characteristics, interests, and medical problems. Currently, there are a huge number of available listening tools, including audio recordings, films, songs in English, audiobooks, radio broadcasts, television channels, and podcasts.

It is recommended that the audio material be associated with the unit that is currently being studied in the classroom, thereby reducing the time for working out the lexical material that was introduced earlier within the framework of the conversational topic, and the logical information chain is not interrupted. When choosing a text for listening, we take into account the level of training of the student, the volume of the sounding text. The teacher's task here is to facilitate the process of perception, remove all kinds of phonetic, lexical, grammatical difficulties even before listening to the text.

Depending on the task, there are:

- Listening with a full understanding of the text

- Listening with an understanding of the main content (listening for detailed information).

When listening with an understanding of the main content, it is enough to present the text twice. If the text is large in volume, then during the second listening, you can make small pauses after a logically completed paragraph. When listening with selective extraction of information, one listening is enough and memorize the basic information, ignoring the secondary and unnecessary.

Listening training can be divided into 3 stages:

- Before listening

- While listening

- After listening.

Let's consider a specific example of a lesson with students of the medical direction at the ASMI.

As part of the study of the topic "The lungs", students are invited to listen to audio recordings of a country-specific nature called "Life without breathing". Tasks before the text stage can be as follows: What do you think this text will be about? (content proposal by title) What is necessary for living? Look at the picture and tell. (visual support, photos can be taken from the Internet). Emphasis is placed on selective vocabulary and grammar. An assignment of this type: Make up your on sentences with new words. For others to listen carefully to the examples of their peers, you can organize the work in this way: the first one reads in English, the other translates the sentence which heard into Uzbek/Russian, thereby concentrating his attention, memorizing new words and developing listening skills.

Results and Discussions

The purpose of the exercises at this stage is preparing students for listening, introduce them to the topic, and motivate them to work, remove any lexical or grammatical difficulties. At the next stage, the textual one, the students listen to the text; try to understand the main content, the topic of the text, the basic facts.

Before listening, teacher can give tasks such as: Listen to the text and tell what sort of text it is (for example a description, an opinion article, a narrative) Listen to the text and think of your own heading. Guess what ... ?. If the text is not of a regional nature, but describes a situation or an incident in the life of the narrator, then you can pause while listening and ask the students to predict, guess how and how the story will end.

After the text stage, it offers endless possibilities for checking the understanding of the material heard, as well as for the parallel improvement of the skills of other types of speech activity. Tasks after the text stage can be as follows: Fill in the gaps. Are the sentences true or false? If the sentence is false, correct it. Put the sentences in chronological order. Choose the correct answer. Match two halves of the sentence. Make a plan of the text. Make up your own questions based on the text. Do you remember what these numbers mean? These tasks simultaneously improve writing and reading 
skills. Another group, after the text exercises, is aimed at improving their speaking skills. This includes exercises like Answer the questions. Choose the best summary. Discuss with your partner. Choose the proverb (think of proverb) according to the text. Do you agree or disagree with the narrator? Who do you agree with? Give your own arguments. This task is suitable if the audio recording is the expression of the views of several people on a problem.

The number of exercises will depend on the level of training, activity and interest of the students, as well as on the amount of time in the lesson. Thus, teaching listening is a rather interesting, rich, educational and cognitive process, if the student is motivated correctly. Possession of this skill ensures the success of communication, which lies in the ability to speak English and understand English. In addition to its main goal, listening develops memory, thinking, imagination and perception, that is, contributes to the all-round development of the personality.

Medical students require not only effective listen but also effective oral and non-verbal communication. When they interact with patients, they have to remember the elements of good verbal communication into if we may add eyecontact, focusing on listening and interactions. After communicating with patients doctors will directly connect with reading-emphasizes the tenets of scientific reading. This means one must accurately communicate complicated scientific information found through complete, discerning and careful research. Developing strong research skills takes time and practice in Uzbekistan without English atmosphere is one of the most difficult aims but deleting reading in the list of necessity of the language is impossible.

From our point of view, to a certain extent, the situation could be changed by including in the mandatory list of literature (journal articles, monographs, textbooks) in English in special medical departments, followed by the requirements for writing abstracts, annotations, and a summary of what has been read. This can be done both in English and in anative language at the discretion of the department. Of course, this imposes additional difficulties on teachers, but at the same time it contributes to the development of their own language competence, helps them to keep abreast of the latest discoveries in the field of medicine in which they are engaged.

Medical students able to know how make analyses and evaluable in their native language. In order to do all these process in English or other non-native all medical institutions and schools have initiated Writing Across the Curriculum (Wac) programs in undergraduate medical programs. Research which was organized in ASMI devoted to the writing and speaking skills of medical students whose first language is not English does not currently exist. It examined the verbal communication skills between doctor and medical students in ESP. In a study of the vocabulary knowledge of medical students whose language is not English found that students lacked fundamental knowledge of certain basic and common pharmacy and health-related vocabulary words in isolation as well as in context, falsely believed that they knew the meaning of certain words, confused phonemically, graphically, and morphologically similar words such as persist in, alleviation, elevation and although they demonstrated better knowledge of some of the simple words when used in context, they continued to exhibit weak word knowledge.

Writing is not an easy task for most students. Many scientists and our research on ESP writing anxiety suggests. There is a link between writing anxiety and self-confidence or selfperception of competence. There is extensive research devoted to the strong relationship between reading, writing and communicational skills are inextricably linked and dependent on vocabulary knowledge. In many ways, the ability to write well is determined by the writer's knowledge of vocabulary. Vocabulary is the biggest challenge for ESP students who are faced with unfamiliar reading text most students believe they know the words or will decide to ignore the 
words they do not know. The ability to write well in a second language is also depend on the students' ability to understand and use grammar. Such students often commit many errors. There are several reasons students commit grammar errors when they write.

According to our research, the methodology of teaching English in a nonlinguistic university, where students acquire knowledge, skills and abilities of their future professional activities, has a number of features. A distinctive feature of teaching English in a nonlinguistic university is the maximum consideration of the specifics of the professional sphere: its concepts and terminology, lexico-syntactic and grammatical features, the format of oral and written texts, and situational features. Therefore, training is built in accordance with specific professionally significant goals and objectives, on the basis of thematically and grammatically selected material, reflecting modern professional (in our case, medical) problems and ways of their practical solution, as well as situations of possible communicative interaction with foreign language representatives.

Conclusion

The main requirement for teaching ESP to read becomes the need to bring the content and methods of teaching it closer to the practical needs of the students, for which it is necessary to carefully study the goals and objectives of the students of a medical university, to take into account their interests and motivation when drawing up a training program. First of all, this relates to the selection of material, its critical understanding, taking into account the future specialization of students and the level of their language competence.

Based on the interest that the experimental teaching of ESP in listening, reading and speaking aroused among the students, one can judge the relevance of the article and the need to develop trainees' skills and abilities to extract professionally significant information from medical texts.

\section{References}

[1] Hudson T. 1982, The effects of induced schemata on the "short circuit" in L2 reading, p. 1-31

[2] P. Johnson, 1982, Effects on reading comprehension of building background fluency, p. 503-516

[3] Carrell P. \&Eisterhold J., 1983, Schema theory and ESL reading pedagogy, p. 553-574

[4] Madden J.F.1980, Developing pupil's vocabulary-learning skills, p. 111-117

[5] Nation, I. S. P. (2001).Learning vocabulary in another language. Cambridge: CUP. p. 27

[6] VitinZh.L. Modern methods of teaching and learning foreign languages. - St. Petersburg: KARO, 1997 .-- 108 p.

[7] Galskova ND, Gez NI Theory of teaching foreign languages: Linguodidactics and methods: Textbook. A guide for students. lingual. Un-tov and fac. in. lang. higher. ped. study. institutions. - M .: Publishing Center "Academy", 2006. - 336 p.

[8] KolkerYa.M., Ustinova E.S., Enalieva T.N. Practical methods of teaching a foreign language. - M .: Academy, 2001 .- 156 p.

[9] Solovova E.N. methods of teaching foreign languages: Basic course of lectures: A manual for studentsped. universities and teachers. - M $\therefore$ Education, 2003 .-- 239 p.

[10] Gorelik P. L. Annotations to medicines in English and Russian: a comparative study // Bulletin of the Academy encyclopedic sciences. 2014. No. 3. S. 55-59.

[11] Gorelik P. L. Linguistic and Cultural Peculiarities of Translation medical prescriptions from English into Russian // Bulletin of the Academy encyclopedic sciences. 2014. No. 3. S. 60-63. 3601

[12] Valeeva N.G. "Introduction to Translation Studies" - Moscow: RUDN University Publishing House, 2006.

[13] Edition of the European Pharmacopoeia in Russian. t. 1. M .: OOO "Remedium", 2011.1816 p. 
[14] Korzhavykh E. A., Moshkova L. V.

Characteristics of research in the field of pharmaceutical terminology // Bulletin of RUDN. Ser. Medicine.Specialty "Pharmacy". 2004. No. 4. S. 80-90.

[15] Oxford Dictionary of English Language, OUP, 2008 